Original Research Paper

\title{
Hybrid, Hybrid Flexible and Fully Online Learning through Students' Eyes
}

\author{
Dolapo Adeniji-Neill, Courtney Lee Weida and Anne Mungai
}

Curriculum and Instruction, Adelphi University, USA

\author{
Article history \\ Received: 11-07-2018 \\ Revised: $21-07-2018$ \\ Accepted: 27-08-2018 \\ Corresponding Author: \\ Dolapo Adeniji-Neill \\ Curriculum and Instruction, \\ Adelphi University, USA \\ Email: dolapo.neill@gmail.com
}

\begin{abstract}
Hybrid and fully online studies and classrooms are no longer fringe elements of learning or knowledge acquisition; they have become integral part of learning in the 21st century. Like all modes and styles of learning, they depend on continuous research for best practices in order to remain relevant in terms of effectiveness and growth. This study is a collaboration between three professors. The courses and students we taught were in Special Education, Adolescence (Secondary) Education and Art Education. There were 35 females and 5 males in the study. Half of participants were graduate students and half - were undergraduate students, total $\mathrm{N}=40$. The participants answered 35 survey questions on their experiences in their hybrid classes at the end of the seminars via surveymonkey.com. The asynchronous hybrid classes utilized technology infused teaching, including online discussion forums, video projects, Power Points with narration and podcasts.
\end{abstract}

Keywords: Technology and Learning, Hybrid and Distance Learning, Online Learning Interactions, Technology Competency, Community of Inquiry Framework

\section{Introduction}

This qualitative research aims to investigate the perceptions of students participating in asynchronous blended courses or online learning in a school of education. "Online learning is the contemporary version of distance education, also called "distance learning" or "open learning." In this educational modality, the majority of interactions between students and instructor, among the student themselves and with the content of the subject matter, occur in the virtual environment of a course management system; namely, a software application capable of managing classes and sections, providing instructional content to them and facilitating student assessment. The term "Learning Management System" or LMS has become more accepted to designate this type of software, also, "Course Management System is often used" (Online and hybrid course manual, Bowie State University, version 2011-2012).

The factors we seek to uncover in our study are students' satisfaction, students' participation, students' perceptions and course design (Swan, 2003), in undergraduate and graduate Education majors' classes.
We hypothesize that blended courses have unique advantages as opposed to traditional brick and mortar classroom and solely online classroom. These advantages include the social context of face-to face interactions as well as the freedom of individual to fully participate without the constraints of narrow time and space that is evident in face-to-face classroom. We also deduced that when students wear the "technology mask" they feel more comfortable discussing the sensitive issues on race and diversity among others. Moore (1989) highlighted three kinds of interactions that may not be at play on online courses; these are interaction with content, interaction with instructor and interaction with classmates. In a blended or hybrid courses, these mitigating "negative" factors should be lessened because of the physical connection of the student at least 33 to 66 percent of the time as in the case in the courses that were the subjects of this research. Garrison et al. (2000, 88), noted, that if we take a deeper look at the "Community of inquiry model of online learning," 


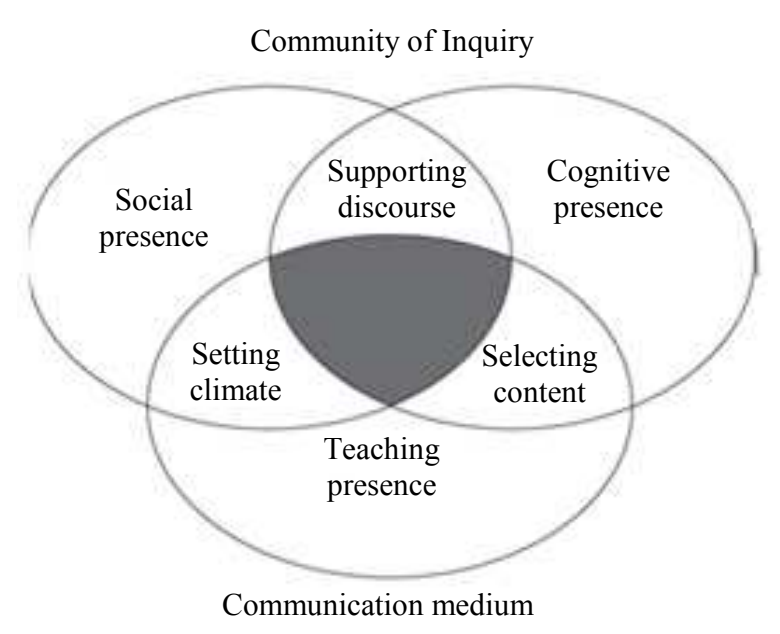

Fig. 1: Community of inquiry. Garrison, D.R., Anderson, T., \& Archer, W. (2000). Critical inquiry in a text-based environment: Computer conferencing in higher educationmodel. The Internet and Higher Education, 2(2-3), 87-105

\section{Literature Review}

Moore and Kearsley (1996) have defined distance learning as a learning environment where students and teachers are separated by distance and sometimes by time' (p. 1). Rovai et al. (2008) emphasized that if any element in structured learning is separated by 'time and/or geography' (p. 1), then the learning takes place in a distance learning setting. Online education is a process by which students and teachers communicate with one another and interact with course content via Internetbased learning technologies (Curran, 2008). A course is considered an online course if $80 \%$ or more of the content is delivered via the Internet. Olson and Wisher (2002) reviewed 47 online course evaluation reports published between 1996 and 2002 and suggested that online instruction 'appears to be an improvement over conventional classroom instruction (p. 11). Furthermore, it is effective and efficient to conduct online courses to support more potential learners to pursue further academic experience under different life conditions (Richardson and Swan, 2003, 69).

Garrison et al. (2000), coined the term "Community of Inquiry framework" (Fig. 1) the framework examine what faculty and students need, to build an effective online learning community. These are teaching presence, a cognitive presence and a social presence.

\section{The Role Shifting in Online Learning}

Online learning opens an avenue for both teachers and students to take new and often enhanced roles in learning and teaching process as compared to face-toface teacher oriented classroom. However, the changes in the roles during online learning have an impact on the relationship between students and teachers, their peers and also the curriculum (Curtis and Lawson, 2001, 23). In other words, we have observed ways in which our students can be at times more engaged in learning discussions and in other cases, completely absent from these discussions within our online courses. It is essential for students to take a more active position in the learning and teaching interactions in online learning than in a face-to-face classroom setting, which is the most efficient way for them to gain useful knowledge in an online setting (Hung et al., 2010, 1080). Also, it is beneficial for the teacher to raise their students' awareness of the new roles in the online format and help them enhance their self-learning abilities, which encourages the students to become more self-directed learners (Hung et al., 2010, 1081).

\section{Students' Competence towards Online Learning}

Students develop competencies that are unique and critical to online learning. These areflexible learning and teaching interactions, independent learning proficiency and strategies, peer collaboration through online discussions and internet-based and computer-based abilities. Those competences are the momentum of a successful online learning process. Essentially, online learning provides flexible schedules and less constraint of places for students to acquire knowledge as compared to traditional face-to-face classroom settings (Hung et al., 2010, 1081). In an online course, students can absorb meaningful knowledge selectively according to their needs, rather than labor on some points that they already know. Online learning could also level the playing field for students with limited resources as in many Universities tuition for online classes are much lower than face to face course tuition.

Students' independent learning proficiency and strategies make them become successful online learners. Obviously, online learning requires students to arrange their own learning schedule and choose materials from the entire course by using various strategies, such as time management, negotiation and critical thinking strategies (Hung et al., 2010, 1082). Students can enhance their independent learning proficiency with teachers' appropriate instructions and scaffolding during their online learning interactions.

Peer collaboration through online discussions is another necessary competence to be successful in online learning. It is imperative that students support each other with good comments and also suggestions in the discussions occurring in an online course. The interactions between peers within online learning activities explore potential knowledge from diverse resources, which is beneficial for both teachers and students.

Online learning has become an integral component of higher education in present world. Taking advantage of 
this factor it has resulted in an increase in number of enrollment without the corresponding wear and tear on main campus infrastructure. Many institutions have added online components to their programs in order to attract more nontraditional students (Tetteh-Richter 2015). Universities also include blended learning, which consists of face-to-face courses and the use of LMS in their multi modal ways of dealing with education and knowledge delivery to students.

\section{Students' Participation and Satisfaction of Online Learning}

It is crucial for educators to encourage the students to participate in an online setting because students' participation is a fundamental element in creating successful online classes. Interactions among students and between students and teachers are of significance in developing students' academic and social competence (Richardson and Swan, 2003, 81). Online learning gives different types of student's opportunities to express their thoughts, confusion and concerns about the current learning experience, which is different from the traditional classroom setting where students have limited time and chances to raise questions and participate (Kim et al., 2005, 336). The more the students participate in a meaningful way, they will expand their knowledge of the content and enhance their social communicating strategies through writing.

Shee and Wang (2008) and Herbert (2006) found that the quality of online instruction depends on student satisfaction and learner interface. It can be seen from previous studies that students show certain satisfactions in online learning; students admire the flexibility (Kim et al., 2005, 336) and convenience of online learning and teaching interventions (Song et al., 2004, 61). Students gain more power and control of their own learning process, which they can learn for diverse goals individually according to the current academic proficiency. It benefits students to decide how much they should learn about particular content and how much they should explore certain aspects.

\section{Authentic Online Course Design}

It is critical for educators to realize how important a course design is for successful online learning interactions. An authentic online course includes efficient course structures, targeted tasks and intriguing activities. A well-designed online course contains tasks that can develop students' critical thinking skills through interactions with their teacher, peers and the materials from the instructions. Students will be motivated to learn additional information if the online tasks are compelling for them.

An authentic online course helps students become engaged in an online setting (Herrington et al., 2003, 59) and even avoid the inherent weaknesses of online setting (Song et al., 2004, 61). It is obvious that online learning may generate a delay of response or sluggish attitude towards learning as compared to teacher oriented faceto-face classes. Also, it is inevitable that online learning presents a non-simultaneous response and ambiguity of focus because online discussions and interactions lack teachers' direct instructions or targeted communication through conversations (Curtis and Lawson, 2001, 22). As the students get more control of the time and effort they can put into studying, it is important to design compelling tasks that help students to keep motivated in each lesson consistently.

Although there are many strengths in online learning interactions, it doesn't mean that we should ignore the weaknesses of them. It is essential for course designers to combine traditional class meetings with online learning activities (Hiltz and Turoff, 2005, 60). In that way, the students will be more responsible for their own learning process and will also have opportunities to achieve direct instructions from face-to-face classroom settings that can be seen as a stimulate atmosphere for them. Additionally, the balance between two kinds of classes will help the educators integrate the students into a united group, which will address another weakness of pure online learning (Song et al., 2004, 62).

\section{Methodology}

This study is a collaboration between three professors. The courses and students we taught were in Special Education, Adolescence (Secondary) Education and Art Education. There were 35 females and 5 males. Half of participants were graduate students and half were undergraduate students, total $\mathrm{N}=40$. The participants answered 35 question-survey on their experiences in their hybrid classes at the end of the seminar via surveymonkey.com. The asynchronous hybrid classes utilized technology infused teaching, including online discussion forums, video projects, PowerPoints with narration and podcasts.

Rationale for the study: As formal education becomes more student-centered and less lecture oriented; and education becomes more computer mediated with the advent of more access to the internet and cheap computers, we believe our study will contribute to more understanding of effective teaching and learning.

\section{Demography}

Students who complete a pilot of blended learning courses in the Curriculum and Instruction Department were asked to complete a reflection questionnaire based on their experience. Feedback will be used to modify blended learning courses in the future.

There was a total of 40 responses to the survey out of 81 students across 7 sections of blended courses $50 \%$ response rate: 


$$
(N=40)
$$

There were 33 questions in this survey. They are summarized into five sections, which are SelfAssessment, Feedback about Online Experience and Students' Interactions in Groups, Comfort Level and Overall Reactions.

\section{Results}

What are the strengths and weaknesses of your own participation in the online portion of this course?

Strengths

\begin{tabular}{ll}
\hline Category & $\mathrm{N}(\%)$ \\
\hline Flexibility and Time Management & $11(33 \%)$ \\
Allows Reflection in Response & $6(18 \%)$ \\
Facilitates Professional Discussion & $5(16 \%)$ \\
Learn from Others & $2(6 \%)$ \\
Other, Misc. & $8(24 \%)$ \\
None & $1(3 \%)$ \\
\hline
\end{tabular}

\section{Strength}

Students' comments on the strengths of hybrid learning were as follow:

- On Flexibility and Time management

- It allows me more time and flexibility to complete assignments

- I complete each assignment on time and give a well thought out answer to all of my posts

- Allows Reflection in Response

- The online portion of the class allows me to fully take in all that we are learning and reflect on it more than we have time to in class. It also allows me to feel like my voice is being heard

- Facilitates Professional Discussion

- One of my strengths I feel is that I have no problem voicing my opinions in my posts. Most often I agree with my peers about their posts and vice versa. Yet there are times

- Learn from Others

- I learned from the other student's responses from the forums. Working independently is a strength of mine

- Seeing what everyone commented clearly and responding more efficiently

- $\quad$ Other, Misc.

- My strengths in participating in the online part of this course is that I have been able to give seriously in-depth analysis of the videos we've watched.

- None

- I do not like taking classes online; I do not feel that I am getting enough out of the class if I am just watching ted talks each week

\begin{tabular}{ll}
\hline Category & $\mathrm{N}(\%)$ \\
\hline Lack of Focus & $8(40 \%)$ \\
Lack of Stimulating Atmosphere & $6(30 \%)$ \\
Difficulty with Access & $3(15 \%)$ \\
Category & $\mathrm{N}(\%)$ \\
Positive & $31(78 \%)$ \\
Negative & $5(12 \%)$ \\
Other & $4(10 \%)$ \\
\hline
\end{tabular}

\section{Weaknesses}

Students' comments on the Weaknesses of hybrid learning were as follow:

- $\quad$ Lack of Focus

- Posting my feedback on time on Moodle. Sometimes, there's just so much going on and the time that you don't have to physically meet in class you can get caught running errands or other important things that takes up your time and side track you, from logging into Moodle to complete the posted assignment

- Lack of Stimulating Atmosphere

- During the online portions the discussion lacks any real agreement or disagreement thus becoming my weakness

- My weakness is that I find it hard to carry real dialogue, conversation or debate in Moodle assignments

- Difficulty with Access

- It takes a bit longer to get the assignment done because of availability to get to a computer

- I try my best to keep up with the online assignments but sometimes I do not have access to a computer and submit the assignment on time. However, I try my best to do it as efficiently as possible

- $\quad$ Other, Misc.

- Sometimes I wish that the online discussions would be brought back into the classroom

- Sometimes it's hard to figure out what to say about other people's responses; sometimes it's a lot to write down for my online response and so I would have to open a Word document to type 
it there, save it and then copy and paste it into Moodle so that I am sure nothing gets deleted

Is the time you are spending in synchronized web work proving to be valuable time spent? How?

\section{Valuable Time Spent}

\begin{tabular}{ll}
\hline Category & $\mathrm{N}(\%)$ \\
\hline Positive & $31(78 \%)$ \\
Negative & $5(12 \%)$ \\
Other & $4(10 \%)$ \\
\hline
\end{tabular}

- Positive

- I believe so because although we are not in the classroom, we are learning a great deal about the material that the course offers

- It saves time in that everything's quickly available and it can be done quickly

- Yes. I don't feel as much pressure to do my work. I can do it on my own time while still getting everything I need to get done finished

- Negative

- Kind of. But I find discussing Category is in a face-to-face setting to be much more valuable, rewarding and beneficial. I'm not a fan of online discussions at all, because, really, it's not a true discussion when people can post whenever they want

- I personally think the work load online is immense. If this were a strictly online course, I would not complain. But we meet 2 times a week in the classroom and are required to post online for all three classes of the week. It is just too much

- Others

- Somewhat

- Yes and no. It can become tiring to constantly be on the computer to complete work

What is the quality and quantity of your dialogue, with peers, on the on-line forum compared to a traditional in-class setting?

\section{Quality}

\begin{tabular}{ll}
\hline Category & $\mathrm{N}(\%)$ \\
\hline High & $14(42 \%)$ \\
Average & $6(18 \%)$ \\
Poor & $10(30 \%)$ \\
Other & $3(10 \%)$ \\
\hline
\end{tabular}

\section{Quality}

- High
- Great to present comments and ideas through an online discussion and receive feedback from peers

- It is easier to respond to peers because I have more time to think about what I want to say

- Average

- I believe that my participation is relatively equal both online and in class

- I think I have time to write out clearer and better worded responses, but I don't think it replicates a real conversation

- Poor

- I believe that my participation is relatively equal both online and in class

- I am more or a traditional in class participant. Being with my peers and having discussion with them face-to-face works better for me than online discussion

- Others

- After I post, I read everyone else's posts thus far. Once I have read them all, I decide which ones I felt most strongly about and choose 2 to respond to

\section{Quantity}

\begin{tabular}{ll}
\hline Category & $\mathrm{N}(\%)$ \\
\hline More Participation Online & $12(48 \%)$ \\
Equal Participation & $5(20 \%)$ \\
Less Participation Online & $5(20 \%)$ \\
Other & $3(12 \%)$ \\
\hline
\end{tabular}

\section{Quantity}

- More participation online

- There was an exponential amount of quality and quantity discussion throughout our online forum. Each student was allotted an appropriate amount of time to gather their thoughts and then reflect on what their peers had to say. Although you feel aspects of emotion and empathy through classroom dialogue, the half and half method was extremely effective

- There is a good amount of dialogue

- Equal participation

- The discussion in both settings is equal to the material and the input from others. We, as students, work well together no matter the setting

- Less participation online 
- I think it's hard to say everything you want to say online, so we tend to have to cut things short on the online forum. However, an online forum allows everyone to really think for themselves and voice their opinions

- Not everyone participates in the online portion

\section{- Other}

- My peers' comments were very helpful

- The dialogue obviously is much different via one line because not everyone is participating at once. When online, to have a thorough discussion, everyone needs to read and respond to each other's posts

\section{Posting to Initial Question}

\begin{tabular}{ll}
\hline Category & $\mathrm{N}(\%)$ \\
\hline Yes & $34(97 \%)$ \\
No & $1(3 \%)$ \\
\hline
\end{tabular}

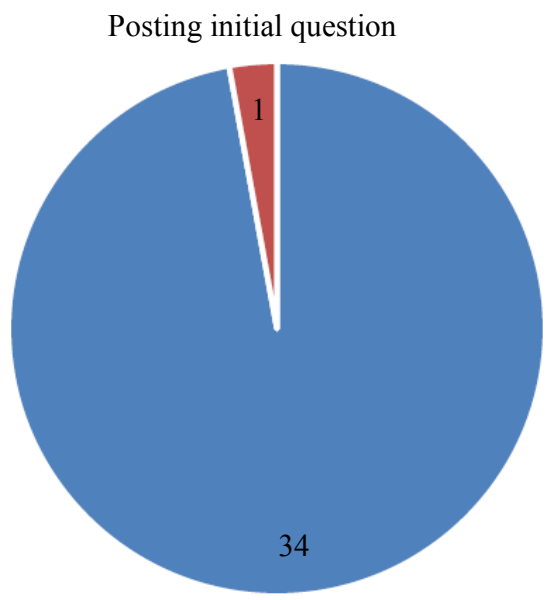

How would you rate the discussions?

Survey Responses: Did you post in discussions?

What is the quantity of your dialogue online and in class?

In Fig. 2, we asked the question regarding the first requirment of students participation online: "Do you post to initial questions on your assignment?" 34 out of 35 students who responded to this question said "yes," except one.

In Fig. 3, 97\% of our paricipants were highly engaged in discussion forum (online discussion or blogging.) This level of participation was unusual when we meet face-to-face because it was not demanded that everyone participate in class discussion due to time constraints; however, while in an online platform, participation is a must; otherwise, the student might not get a favorable grade if he or she did not participate. Not participating in an online forum is equal to being absent in the classroom.

Fig. 2: Number of students who posted to initial questions on Moodle assignments

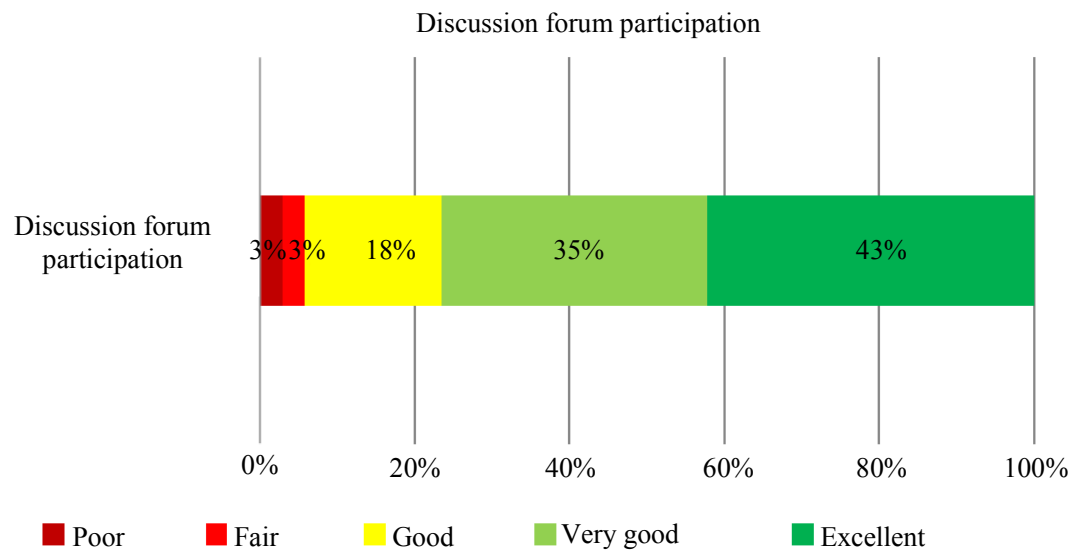

Fig. 3: Students participation in discussion forum 


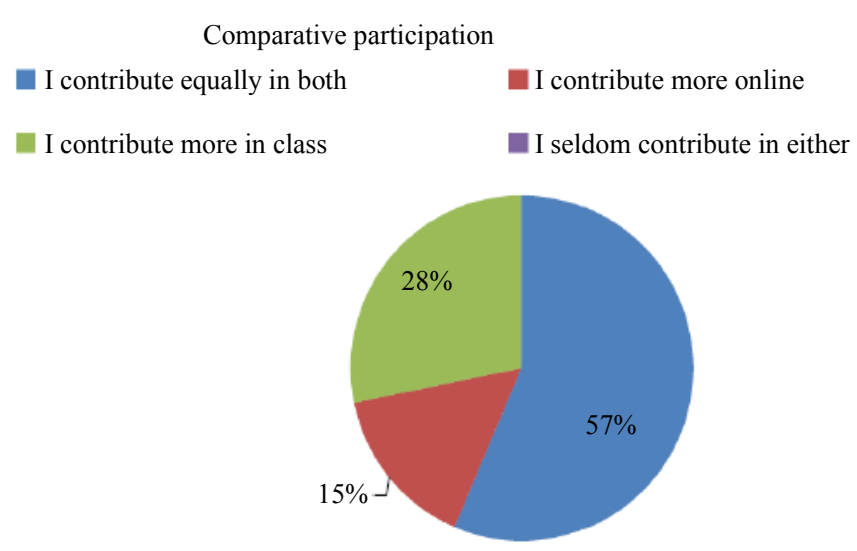

Fig. 4: Comparative participation and contribution in online vs. Face-to-face classes

In Fig. 4, 57\% of our participants indicated that they contributed more in online class than in face-to face class; while $15 \%$ contributed equally in both modes of instructions. However, $28 \%$ prefer classroom instruction. The high level of contribution may be due to what we called "technology mask." In this situation, a person is able to offer more of their opinion without the fear of instant judgment from others. A participant also noted that, she was able to do the work required in her hybrid class without pressure and in her own pace; therefore, she was able to contribute more to discussion and that the quality of her involvement improved.

\section{Students' Interactions in Groups}

\section{Group Work Reaction}

\begin{tabular}{ll}
\hline Category & $\mathrm{N}(\%)$ \\
\hline Positive & $29(83 \%)$ \\
Negative & $6(17 \%)$ \\
\hline
\end{tabular}

\section{Students Group Reaction}

- Positive

- I found it helpful. We shared a lot of ideas and experiences that we have gone through. Being an undergraduate student working with graduate students is good to learn

- I enjoy working with groups because it keeps me motivated in doing the work

- Negative

- Based on the content of the course group work was to be expected. I understand the fundamentals of group work but personally enjoy and learn more as an individual

- My group was compliant and effective but I completely disagree to group work in graduate level. Many graduate students are fully employed and complete their work on their own schedules. To manipulate a group to meet at a particular time is very hectic and difficult. I much rather do independent work and complete it at my own rate

Worked in Group Before

\begin{tabular}{ll}
\hline Category & $\mathrm{N}(\%)$ \\
\hline Always & $5(12 \%)$ \\
Frequently & $19(47 \%)$ \\
Occasionally & $9(23 \%)$ \\
Rarely & $6(15 \%)$ \\
Never & $1(3 \%)$ \\
\hline
\end{tabular}

Worked in Group Before

- Always

- I am always working in teams at my place of employment as well as during my undergrad studies

- I work in groups constantly in my other courses. -In every class

- Frequently

- I worked in groups very often

- Frequently, but it is not as easy to work with other groups. It is easiest when the student is comfortable and knows and trusts their partners

- Occasionally

- Often but not many times. Maybe once or twice per semester

- Mostly only when I was in high school

- Rarely

- Not many times- last semester for my science class but that's really it

- Not that much

- Not often

- Never

- Never, this is my first time 
Did you enjoy the online assignments?

Figure 5: Majority of our participants (76\%) indicated that they actually enjoyed the E-tasks demanded of them in the online portion of the class; while $24 \%$ said they did not. The students who expressed dissapointments noted that they found navigating the Moodle learning management platform (MLMP) difficult. And, because the Island in which the University we studied was located experienced a natural disaster (a hurricane) during this study, some students found it dificult to get internet services which were required for completing their class assignments.

In Fig. $6,12 \%$ of the participants found the workload overwhelning and much more demanding than face-toface class workload. A student indicated that because she registered late due to financial aid delay, she was unable to access the MLMP; therefore, she struggled to catch up with her assignments.
Do you find your workload of the e-tasks (online assignments) easy to manage?

In Fig. 7, the majority of our participants (89\%) were satisfied with the ease of navigating the MLMP where they access their course materials and submit assignments. $11 \%$ who had problems navigating the sites reported that they at- times they were unable to find websites posted by thier professors.

They also reported that they had problems with the navigation of some websites; and noted the biggest/most frustrating technical problems they encountered below:

\section{Technical Problems}

\begin{tabular}{ll}
\hline Category & $\mathrm{N}(\%)$ \\
\hline Moodle & $7(18 \%)$ \\
Navigation & $5(12 \%)$ \\
Broken Links & $3(8 \%)$ \\
None & $17(42 \%)$ \\
Other & $8(20 \%)$ \\
\hline
\end{tabular}

Enjoyment of E-Tasks

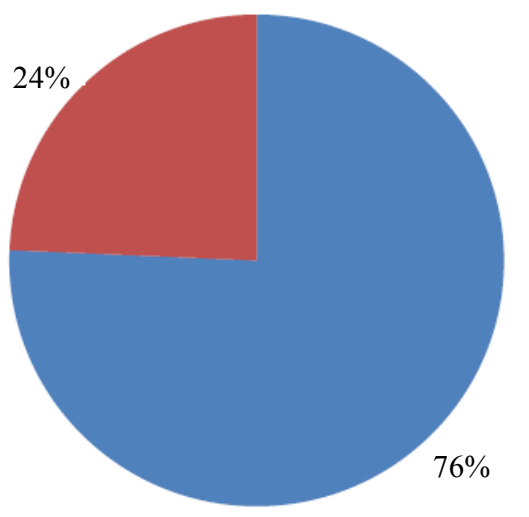

Fig. 5: Enjoyment of E-Task

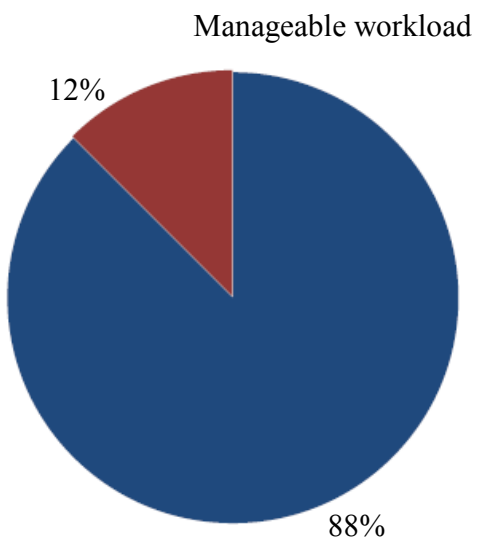

Fig. 6: Manageable workload 
Ease of navigating moodle website

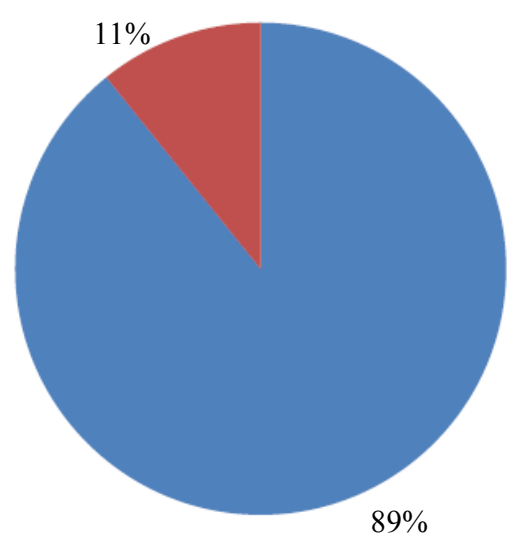

Yes

No

Fig. 7: Navigating Moodle website.

Students Noted the following Technical Problems:

Moodle:

- Initially understanding of the whole Moodle process (like differentiating between "assignments" and "forums"). But after you get used to it, it gets easier. Definitely takes an organized teacher. -Sometimes my posts would take a while to upload and I would miss the date because I had some problems with my eCampus. However, IT fixed it and since then my Moodle assignments became easier to manage

- Navigation:

- Sometimes the assignments were unorganized, but for the most part there were minimal technical problems

- Trying to find assignments, because sometimes there was a lot to navigate through online

- Broken Links

- Incorrect website links

- Sometimes not being able to find the sources necessary--because it wasn't clearly indicated. Or if the Moodle page/dates weren't set up correctly. But my professor was pretty good in this regard

- None

- I did not have any

- None, during my initial use of Moodle I had difficulty responding or replying to the questions, I utilized the Moodle tutorial

- Others

- Websites not being available. Obviously, the hurricane was the cause to many frustrating and technical problems
- I have a faculty e-Campus account and student. I register under my faculty account to get tuition remission. In the beginning of the class I could not find the Moodle account until I emailed for IT for help

What would you suggest for ways that students might become more familiar and comfortable with technology used for delivery of this course?

\section{Technical Problems}

\begin{tabular}{ll}
\hline Category & $\mathrm{N}(\%)$ \\
\hline Practice Moodle & $8(31 \%)$ \\
Demonstration & $5(19 \%)$ \\
No Suggestion & $9(35 \%)$ \\
Others & $4(15 \%)$ \\
\hline
\end{tabular}

\section{Technical Problems}

- Practice Moodle

- Clicking around Moodle to become comfortable of where things are located. - Learn how to navigate Moodle

- They need to understand how Moodle works

- Demonstration

- As an Adelphi student Moodle is used on a regular basis. No need to be taught anything in advance

- Think it's pretty clear but taking the time to read what your classmates had to say

- In this age of technology just sit in front of the computer and figuring it out

- No suggestions 
- As an Adelphi student Moodle is used on a regular basis. No need to be taught anything in advance

- I think it's pretty clear but taking the time to read what your classmates had to say

- In this age of technology just sit in front of the computer and figuring it out.

- Others

- Ask your professor, a friend/sibling that's familiar with the website, or the IT help desk at the library

- More organized sections and better explanations of assignments

Over all Reaction to Web in Teaching Class

Effective Web Use

\begin{tabular}{ll}
\hline Category & $\mathrm{N}(\%)$ \\
\hline Positive & $35(88 \%)$ \\
Negative & $5(12 \%)$ \\
\hline
\end{tabular}

In Fig. 8, we asked students what were the likelyhood that they would take another hybrid course? $68 \%$ of our participants indicated that they will very likely take another hybrid class; while $32 \%$ said: "not likely." Some of the reasons given by the particpants who are not likely to take another hybrid class centered around the need for more physical contact with others.

\section{Effective Web Use}

- Positive

- Yes, it also saved time and we were able to cover a lot of the curriculum, as oppose to only attending the class. We completed the reading requirements, discussed them online as well as attending class for other discussions and topics in the curriculum

- Yes. Online discussions were effective in hearing different opinions and ideas

- Negative

- No. All we have done is watch TED talks, most of which were of the same speaker. So, there is no real diversity in the content and nothing about the web was used. There is an unbelievable amount of really interesting and useful open source education websites and projects out on the internet and not a single one of them was utilized

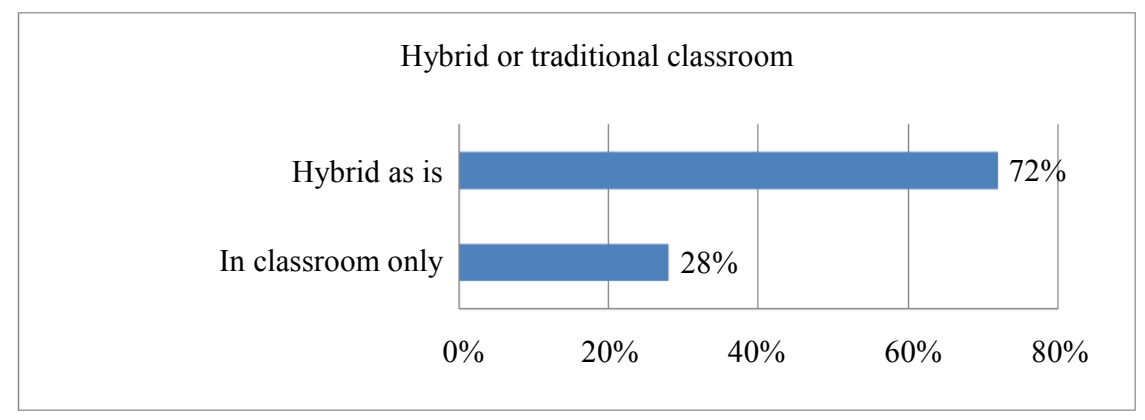

Likelihood of taking another hybrid course

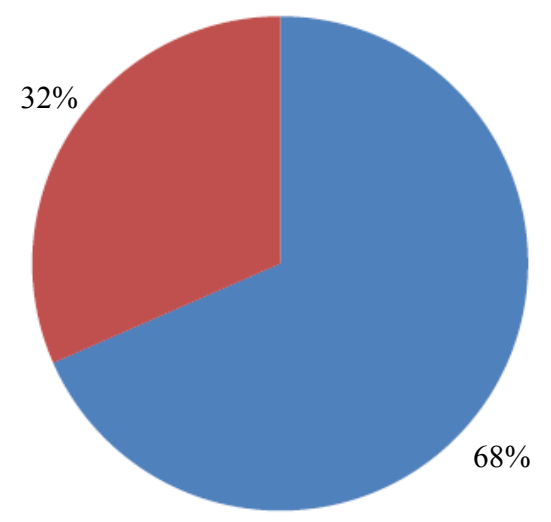

Very likely

Not likely

Fig. 8: The likelyhood of students taking another hybrid course 


\section{Surprise about Hybrid Course}

\begin{tabular}{ll}
\hline Category & $\mathrm{N}(\%)$ \\
\hline Learning Experience & $12(29 \%)$ \\
Hybrid Aspect & $9(23 \%)$ \\
Online Portion & $9(23 \%)$ \\
Enjoyment & $2(5 \%)$ \\
Nothing & $8(20 \%)$ \\
\hline
\end{tabular}

\section{Surprise About Hybrid Course}

- Learning Experience

- The flexibility of this class in correlation to my other life demands

- The amount I'd learn by reading and researching myself

- How well I was able to manage my time and still fulfill work responsibilities

- Hybrid Aspect

- I had never taken an online class before so I was a little shocked. Fortunately, I was pleasantly surprised and enjoyed taking this blended course

- I have never experienced a hybrid course before so this was different for me

- Online Portion

- That discussions in class can be just as powerful online

- I enjoyed the Moodle discussions

- People could be very frank online as opposed to in class and that you were given more time to reflect versus talking in person in class

- Enjoyment

- That I enjoyed it

- I liked it a lot more than I expected

- Nothing

- Nothing really because I have taken these type of hybrid classes before so it is pretty much what I expected

- Nothing, I took a course like this before at another university

Dislikes About Class

\begin{tabular}{ll}
\hline Category & $\mathrm{N}(\%)$ \\
\hline In Person Interaction & $9(23 \%)$ \\
Participation & $4(10 \%)$ \\
Time Management & $4(10 \%)$ \\
Nothing & $17(43 \%)$ \\
Other & $6(15 \%)$ \\
\hline
\end{tabular}

\section{Dislike About Class}

- In Person Interaction

- I felt that things were a little disjointed because we had 2 weeks between every time we met face to face

- I prefer more of a classroom discussion, but it was a nice change to have some online discussions

- Participation

- I feel like some people including myself posted before the assignment was due which left some people out who did the assignment on time

- Not everyone participates online so it is hard to discuss

- Time management

- Remembering to put up my post at a certain time when we don't have to physically meet that week

- The length, it is hard to sit through 2 hours of class without a break

- Nothing

- Honestly, I don't dislike anything

- I have no negative statements about the online classes

- I don't have any dislike

- Others

- The only thing I would have to offer is the idea to go completely on-line with this course. I think it would be manageable and just as effective

- Sometimes I was unclear with the directions

Best Section of the Course

\begin{tabular}{ll}
\hline Category & $\mathrm{N}(\%)$ \\
\hline Presentations and Discussions & $10(25 \%)$ \\
Online Section & $8(21 \%)$ \\
Use of Mediums & $4(10 \%)$ \\
Everything & $3(8 \%)$ \\
Relation to Teaching & $3(8 \%)$ \\
Hybrid Aspect & $2(5 \%)$ \\
Other & $9(23 \%)$ \\
\hline
\end{tabular}

\section{Best Section of the course}

- Presentation and Discussions

- Great course. I enjoyed the material and discussions held in class. I enjoyed the different values and ideas presented from each student in the class

- I liked the group projects, we really got to know each other because of the small class and the 
online discussions really helped us understand each other's views

- Online Selection

- Being able to see what my classmates commented on my writings

- The online portions and projects

- Use of Mediums

- I liked every class; the Professor always used different mediums to address the needs of all the learners. Videos, pictures etc

- The one where we watched the video and the one where we went to the lecture

- Everything

- I enjoyed the entire course and learned in each section taught

- I really enjoyed learning about all of the sections- they were all very interesting and I learned a lot

- Relation to teaching

- The one time we went to class and taught a lesson

- I really liked the discussion leaders' assignments because it allowed us to practice how to conduct a classroom discussion for our future careers

- Hybrid aspect

- Alternating between classroom discussion at Adelphi and course content online

- Not everyone participates online so it is hard to discuss

- Others

How would you characterize your learning experience?
Categorized Learning Experience

\begin{tabular}{ll}
\hline Category & N (\%) \\
\hline Positive & $37(92 \%)$ \\
Negative & $3(8 \%)$ \\
\hline
\end{tabular}

Categorized Learning Experience

- Positive

- As a good one in that I gained more insight towards perspectives of learning and teaching which is exactly what this class is supposed to do!

- Beneficial learning experience. I feel I have learned a great amount of information through this course.

- $\quad$ Effective and eye-opening

- Negative

- I don't really feel like I've learned anything. And I've really tried to get something out of it, but we just haven't done anything meaningful

- I don't feel I learned much of anything

In Fig. 9, Students were asked about their level of participation and the efforts they put into the online section of their courses; $94 \%$ responded that they were highly involved and they were positively affected by their courses. They felt they gained more knowledge: such as "the knowledge of the different cultures and the way that everyone was open minded and tries to change their ideas." And in one class, a studen said, "I was made aware of Gender inequality that persisted in the world through readings, lecutres and discussion forums."

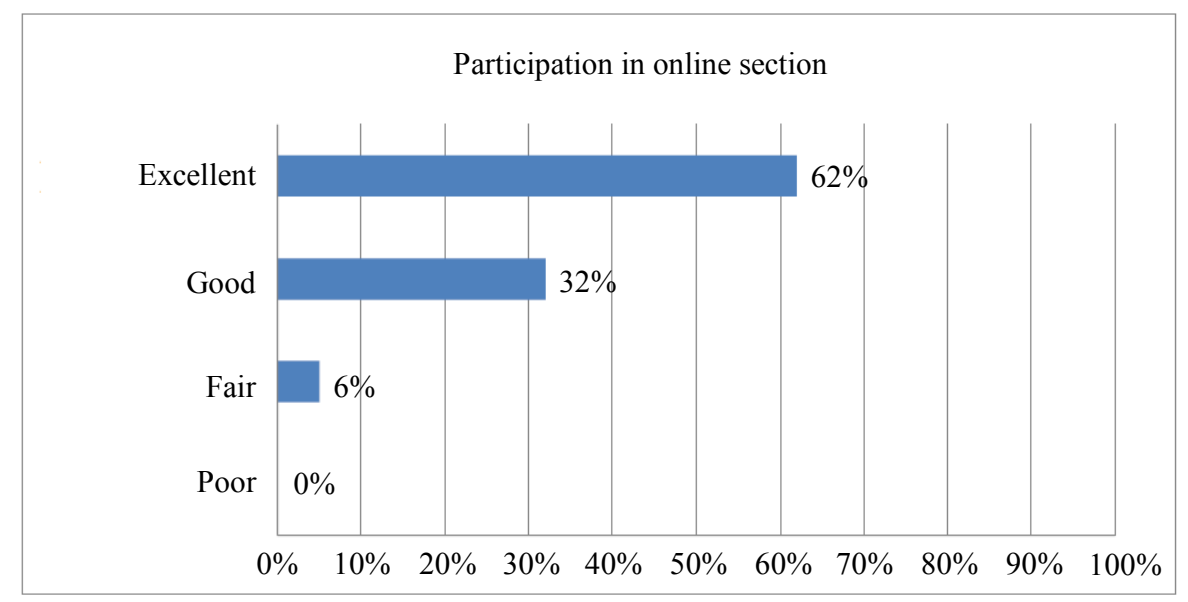

Fig. 9: Students' participation in online sessions 


\section{Additional Observations from Faculty Perspectives}

- Additional time and space for conversation

- "Technology mask" can aid in complex and sensitive topics such as race, gender and cultural diversity

- Development of skill in communicating orally and then in writing about the same topic (transfer of knowledge in a different context) Criticisms of Hybridity

- Students reported some difficulties around lack of focus in course content online

- A lack of stimulating atmosphere online

- Difficulty with accessing course websites

- "do not like taking classes online" Implications and Additional Discussion

- Using hybrid learning as a tool within universal design and/or multidisciplinary, multimodal approaches

- Considering the senses and hands-on engagement in class and as complement to computer and/or tabletbased activities

- Issues of digital and critical literacy perhaps mad more relevant in a hybrid learning environment

\section{Conclusion}

Students in our study support previous research validation that learning activities among teachers and students provide a possibility to generate positive communications and interactions with each other. Students noted that they had more time to think about content and ruminate on what they learned and they acquired fresh knowledge, which raise their satisfaction towards online learning. 37 of the 40 participants characterized their hybrid format learning experience as positive; while 3 participants disagree and found no use for online experiences of the courses. There are many research and studies currently underway because of the popularity of online and hybrid courses; we are very confident that researchers would take our study further in order to continue to understand this new phenomenon in the field of knowledge production.

\section{Acknowledgment}

May thanks to all our students who participated in this research.

\section{Author's Contributions}

Dolapo Adeniji-Neill: Designed the research plan, participated in research procedure, coordinated data analysis, and organized the study, data and, literature reviews, and conclusion. She is the principal writer of this manuscript. She is instrumental in drafting the article, revising and reviewing it critically for significant intellectual content.

Courtney Lee Weida: Participated in research procedure, contributed to analysis and conclusion. She also contributed to reviewing it critically for significant intellectual content.

Anne Mungai: Participated in research procedure, contributed to analysis and conclusion. She also contributed to reviewing it critically for significant intellectual content.

\section{Ethics}

No injuries to humans or animals in the conduct of this survey. Publication of this manuscript should help schools serve their students better by understanding how different delivery modes of educational experiences help or hinder students' success.

\section{References}

Curran, C., 2008. Online Learning and the University. In: Economics of Distance and Online Learning: Theory, Practice and Research, Bramble, W.J. and S. Panda, (Eds.), Routledge, New York, pp: 26-51.

Curtis, D.D. and M.J. Lawson, 2001. Exploring collaborative online learning. JALN, 5: 21-34.

Garrison, D.R., T. Anderson and W. Archer, 2000. Critical inquiry in a text-based environment: Computer referencing in higher education. Internet Higher Educ., 2: 87-105.

DOI: 10.1016/S1096-7516(00)00016-6

Hung, M.L., C. Chou, C.H. Chen and Z.Y. Own, 2010. Learner readiness for online learning: Scale development and student perceptions. Comput. Educ., 55: 1080-1090.

DOI: 10.1016/j.compedu.2010.05.004

Herbert, M., 2006. Staying the course: A study in online student satisfaction and retention. Online J. Distance Learn. Admin., 9: 1-12.

Herrington, J., R. Oliver and T.C. Reeves, 2003. Patterns of engagement in authentic online learning environments. Australian J. Educ. Technol., 19: 59-71. DOI: 10.14742 /ajet.1701

Hiltz, S.R. and M. Turoff, 2005. Education goes digital: The evolution of online learning and the revolution in higher education. Commun. ACM, 48: 59-64. DOI: 10.1145/1089107.1089139

Kim, K.J., S. Liu and C.J. Bonk, 2005. Online MBA students' perceptions of online learning: Benefits, challenges and suggestions. Internet Higher Educ., 8: 335-344. DOI: 10.1016/j.iheduc.2005.09.005

Moore, M.G., 1989. Three types of interaction. Am. J. Distance Educ., 3: 1-6. DOI: $10.1080 / 08923648909526659$ 
Moore, M.G. and G. Kearsley, 1996. Distance Education: A Systems View. 1st Edn., Wadsworth Publishing, Belmont, CA.

Olson, T. and R. Wisher, 2002. The effectiveness of web-based instruction: An initial inquiry. Macmillan Reference USA.

Richardson, J.C. and K. Swan, 2003. Examining social preference in online courses in relation to students' perceived learning and satisfaction. JALN, 7: 68-88.

Rovai, A.P., M.K. Ponton and J.D. Baker, 2008. Distance Learning in Higher Education: A Programmatic Approach to Planning, Design Instruction, Evaluation and Accreditation. 1st Edn., Teachers College Press, ISBN-10: 0807748781, pp: 224.

Shee, D.Y. and Y. Wang, 2008. Multi-criteria evaluation of the web-based e-learning system: A methodology based on learner satisfaction and its applications. Comput. Educ., 50: 894-905.

DOI: 10.1016/j.compedu.2006.09.005
Song, L., E.S. Singleton, J.R. Hill and M.H. Koh, 2004. Improving online learning: Student perceptions of useful and challenging characteristics. Internet Higher Educ., 7: 59-70.

DOI: 10.1016/j.iheduc.2003.11.003

Swan, K., 2003. Learning effectiveness online: What the research tells us. Elements of Quality Online Education, Practice Direction, 4: 13-47.

Tetteh-Richter, D., 2015. Perceptions of adult learners' readiness in Ghana for online instructions in higher education. Available from ProQuest Central. (1752118605). 